\title{
Tradable Refugee-admission Quotas (TRAQs), the Syrian Crisis and the new European Agenda on Migration
}

\author{
Jesús Fernández-Huertas Moraga ${ }^{1,2^{*}}$ and Hillel Rapoport ${ }^{3,4,2}$
}

\author{
* Correspondence: \\ jesus.fernandez-huertas@uam.es \\ 'Universidad Autónoma de Madrid, \\ Madrid, Spain \\ ${ }^{2} \mathrm{ZZA}$, Bonn, Germany \\ Full list of author information is \\ available at the end of the article
}

\begin{abstract}
The Syrian Civil War gave rise to the largest refugee flight reaching Europe since the Yugoslavian wars in the 1990s. The crisis evidenced the deficiencies of the European Union Asylum Policy, which struggled both to offer solutions to Syrian refugees and to efficiently allocate costs across Member States. We draw on previous theoretical work to simulate how a system of tradable refugee-admission quotas coupled with a matching mechanism assigning refugees to their preferred destinations and destinations to their preferred types of refugees would give more flexibility to Member States while respecting refugee rights and preferences.

JEL codes: F22, F5, H87, I3, K33, 019.

Keywords: Immigration policy, EU policy, Tradable quotas, Refugee resettlement, Asylum seekers, International public goods
\end{abstract}

\section{Introduction}

"Nine member states in the EU today receive 90\% of all asylum applications annually, but those nine states are starting to, well, become fed up."

(Tobias Billström, Sweden's Immigration Minister, 3 March 2014)

'This worst humanitarian crisis of our era should be galvanizing a global outcry of support, but instead help is dwindling. With humanitarian appeals systematically underfunded, there just isn't enough aid to meet the colossal needs-nor enough development support to the hosting countries creaking under the strain of so many refugees." (António Guterres, UN High Commissioner for Refugees, 12 March 2015)

UN High Commissioner for Refugees António Guterres referred to the Syrian refugee crisis as the "worst humanitarian crisis of our era," with almost 4 million Syrians concentrated in refugee camps in Turkey, Lebanon, Jordan, Iraq and Egypt in bleak conditions at the beginning of 2015. ${ }^{1}$ A year earlier, Tobias Billström, Sweden's Immigration Minister, complained that most asylum applications in the European Union were handled by only nine countries, his own included, an asymmetry that was leading even the most welcoming countries in Europe to reconsider their willingness to help.

\section{Springer}

C 2015 Fernández-Huertas Moraga and Rapoport. Open Access This article is distributed under the terms of the Creative Commons Attribution 4.0 International License (http://creativecommons.org/licenses/by/4.0/), which permits unrestricted use, distribution, and reproduction in any medium, provided you give appropriate credit to the original author(s) and the source, provide a link to the Creative Commons license, and indicate if changes were made. 
This refugee crisis in the neighborhood of the European Union put EU policies and institutions dealing with refugees and asylum seekers under heavy pressure to reform. The emergency humanitarian situation and the sheer volumes involved acted as stress-tests for the "Common European Asylum System" (CEAS). It is only fair to say that, by and large, the system was unable to provide appropriate responses to the new situation. In Guterres' words: "If we fail to provide adequate support to refugees and their hosts, and to build up their resilience to cope with the long-term pressures of this increasingly protracted refugee situation, we risk a further destabilization of the entire region." ${ }^{2}$ Sadly enough, the CEAS remained largely virtual for a long time, prompting strong criticism of its legal framework (see De Bruycker et al., 2010); at the same time, the pressure to "do something" generated frantic policy experimentation, with a succession of spectacular but often short-lived initiatives, such as the "Mare Nostrum" operation (Fargues and Bonfanti, 2014; Fargues and Di Bartolomeo, 2015).

In May 2015, the European Union launched the new European Agenda on Migration (European Commission, 2015a). The Agenda called for triggering, for the first time, the "emergency response system envisaged under Article 78(3) TFEU," including “a temporary distribution scheme for persons in clear need of international protection to ensure a fair and balanced participation of all Member States to this common effort".

This paper goes two steps beyond the European Agenda on Migration with a proposal on how to coordinate policy responses across Member States in response to refugee crisis. Our proposal builds on well-established models in public economics (markets for tradable quotas) and on recent theoretical contributions in the field of mechanism design (the "matching" component in what follows). These tools have been successfully applied to issues as diverse as pollution, kidney transplants, or to the allocation of students to schools, colleges and hospitals. With some adaptation, they can also be applied to improve the EU's asylum and refugee-admission policy in terms both of efficiency and equity.

The system would have two key elements: the market for refugee-admission quotas and the matching mechanism. In the market, countries would trade quotas previously assigned according to an allocation key like the one proposed in the European Agenda on Migration (European Commission, 2015a). This would make sure that countries more willing to host refugees would welcome more of them and be compensated for doing so by countries less willing to host refugees. The second element, the matching mechanism, is needed in order to make sure that refugee rights are respected at all times. In particular, it guarantees that no refugee is forced to go to an undesired destination. In addition, it generates further efficiency gains by allowing refugees to choose their preferred destinations and countries their preferred, if any, types of refugees.

The full model was developed in Fernández-Huertas Moraga and Rapoport (2014) and adapted to the EU Asylum Policy in Fernández-Huertas Moraga and Rapoport (2015). This paper shows how such a system could work in the context of the Syrian refugee crisis. We first describe the theory behind the proposed system and then proceed to simulate the market side of the proposal under different parameterizations. We conclude with a summary of the main insights from our analysis and by discussing the need for experimentation before undertaking major reforms of the CEAS. 


\section{The proposal}

In earlier work (Fernández-Huertas Moraga and Rapoport, 2015), we set out a "tradable refugee-admission quotas (TRAQs) system with matching" in four steps. The first one is borrowed from earlier proposals, including the European Agenda on Migration. Numbers 2 and 3 refer to our proposal proper, while number 4 just relates it to existing policies, as reflected in an EU pilot project.

\subsection{The distribution Key}

First, we start by documenting the general recognition in both academic and policy circles for the need to reform the CEAS and the need to structure EU asylum policy reform around a number of core legal and institutional principles; first among them is the notion of solidarity, both internal (sharing responsibility among EU member countries) and external (providing refugee protection to those who most deserve it). Regarding "responsibility-sharing" (often improperly referred to by the less politically-correct term "burden-sharing"), we recall the findings of studies (notably Hatton, 2012, and Thielemann et al., 2010) trying to assess the fair share of refugees and asylum seekers each EU country should take according to its "capacity." For example, Thielemann et al. (2010) suggest that based on an "equal burden sharing rule" (assessed by a "combined capacity index"), more than one third of the asylum seekers that were present within the EU borders in 2010 should have been transferred to other countries within the EU. Wagner and Kraler (2014) compare up to seven different quota distribution rules that have either been proposed or implemented within countries. Their implications in terms of the share of asylum seekers that should be allocated to each EU Member State are shown in Fig. 1:

The rules are the following:

1. SWP Model: 40 percent economic strength (GDP), 40 percent population size, 10 percent geographic area and 10 percent unemployment rate.

2. German Proposal 1994: one-third population size, one-third geographic area and one-third economic strength (GDP).

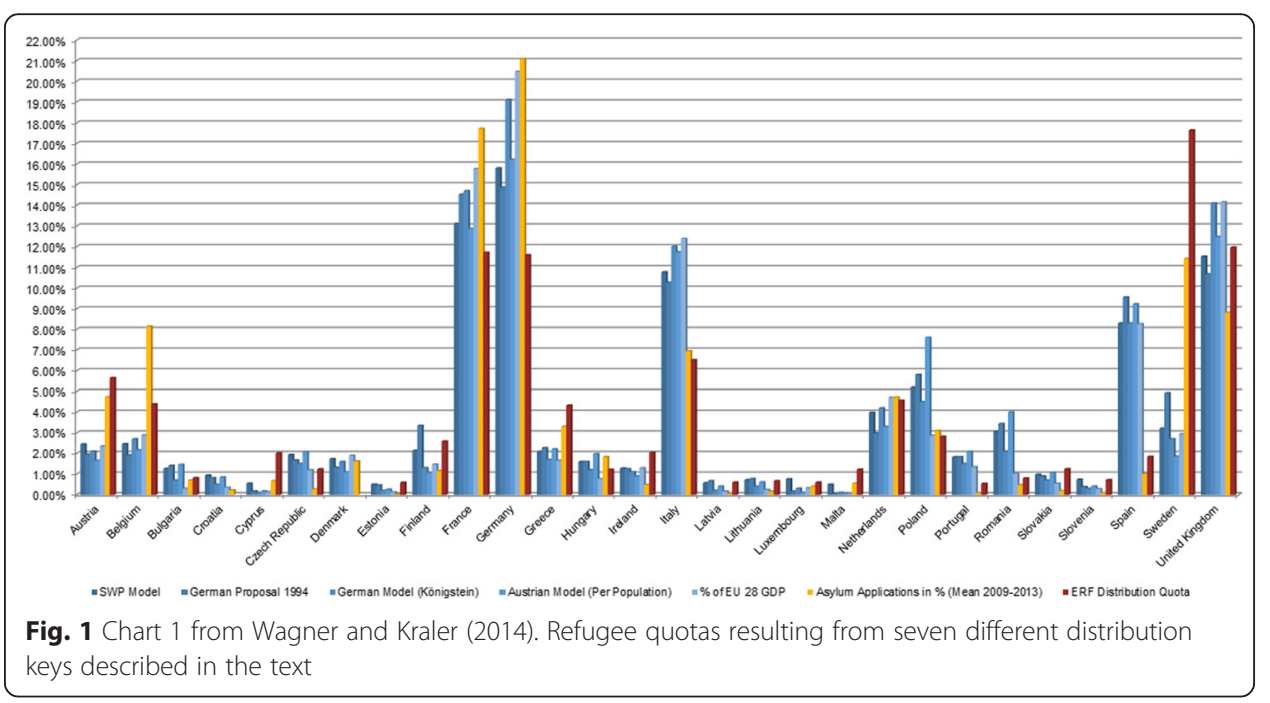


3. German Model for internal dispersal: one-third population size and two-thirds share in total tax revenue.

4. Austrian Model for internal dispersal: population size.

5. Share of EU GDP or economic strength.

6. Mean Asylum Applications in 2009-2013.

7. European Refugee Fund distribution key: 30 percent based on number of beneficiaries of international protection admitted in the last three years and 70 percent based on number of applicants for international protection admitted in the last three years.

Figure 1 shows that rules 1 to 4 give rise to similar distributions of quotas, based mostly on economic strength and population, which are typically highly correlated. Rules 6 and 7 are a bit different as long as they are based on actual applications and refugees accepted by the countries. In this sense, they can be seen as having an inertia component, which can alternatively be interpreted as either maintaining the status quo or else as reflecting revealed preferences on the part of Member States.

The European Agenda on Migration (European Commission, 2015a) introduced an eighth distribution key with the following components (European Commission, 2015b): a) the size of the population (40\% weighting), b) the total of the GDP (40\% weighting), c) the average number of spontaneous asylum applications and the number of resettled refugees per one million inhabitants over the period 20102014 (10\% weighting) and d) the unemployment rate (10\% weighting). Hence, it is basically a replication of rule number 1 that substitutes the geographical area element with something similar to rules 6 and 7, although used in the opposite direction. Rather than to ensure some inertia, the inclusion of the previous number of resettled refugees aims at relieving the efforts of those countries that received more refugees in the past.

Next, we detail the two components of our proposed mechanism, which are borrowed from the broader scheme developed in Fernández-Huertas Moraga and Rapoport (2014).

\subsection{The market for tradable refugee-admission quotas}

The first component is the tradable quotas system. Its principle is to determine a total number of asylum seekers/refugees to be hosted by the EU and a distribution of initial quotas across countries. We are agnostic with respect to the total number and the initial allocation, which could be done according to any of the eight rules mentioned above. These issues must be addressed in any solidarity mechanism, not just ours. The advantage of a tradable quotas system, however, is that it allows for revealing information on the true costs of accommodating refugees in the participating countries, and it allows (actually, forces) countries to exploit their comparative advantages in either "hosting" or "funding." In other words, there are two ways by which countries can contribute to the public good of the "international protection of refugees:" through visas or through money. The market for admissions will allocate refugees so that the marginal cost of hosting them is equalized across destinations. The solution is efficient in that it minimizes the total cost (or, for a given total cost, allows for the accommodation of more refugees). 
Of course, for such a system to bring about benefits that exceed its set-up costs, there must be large cross-country differences in the costs of admitting refugees and asylum seekers. This will be more likely the case if countries are more dissimilar in their assessments of how "costly" refugees' admissions are (which in turn depends on how dissimilar they are in terms of economic performance, demographic structure, intrinsic preferences for diversity and cultural proximity, and any other dimension affecting the actual and perceived costs of hosting refugees). Finally, it is also important to assess the extent to which the EU Member States are opened to financial compensations among them as potential solidarity mechanisms. Thielemann et al. (2010) suggests that financial compensation is among the preferred mechanisms (together with information sharing and joint capacity-building) to put solidarity in the field of asylum policy into practice.

\subsection{The matching mechanism}

The second component is the matching mechanism, whereby each candidate refugee (e.g., an asylum seeker or a refugee applying for resettlement within the EU) is asked to rank his or her preferred destinations. This means that they would prefer to be resettled in that destination (or have their asylum request examined there) rather than remaining in their current situation. Under no circumstance would a refugee or asylum seeker be forced to go to an undesired destination.

There are several matching mechanisms that could be compatible with our scheme. For example, we could have a one-sided matching mechanism in which only refugees and asylum seekers would express their preferences about their preferred destinations, while destination countries would have no say. In that case, candidate refugees would be ranked in a random order, with the first in line granted their first choice, the second in line their first choice, etc., until we have to go down the list as preferred destinations gradually fill up. This is known as the top trading cycles mechanism, which would be equivalent to a random serial dictatorship (the first in the line "dictates"). This mechanism is typically used for allocating students to housing units in a campus (Abdulkadiroglu and Sonmez, 1999).

However, the matching mechanism does not need to limit the choices of the receiving countries. EU hosting countries could also express their preferences, this time vis-à-vis the "type" of refugees they would like to host. For example, countries could express preferences according to the skill or education level of the refugees, their nationality, family status, or legal status (e.g., asylum-seekers vs. refugees applying for resettlement). This is done by "bidding" for certain types as part of the country's quota. If all countries have the same preferences, the result will be equivalent to a case where they are indifferent with respect to refugee type. If countries have diverging preferences, then allowing them to express these preferences will reduce the expected cost of the system.

Matching mechanisms in which both refugees and Member States could state their preferences are typically used to assign students to schools or colleges. Several mechanisms would be feasible, such as the student-proposing deferred acceptance mechanism. Fernández-Huertas Moraga and Rapoport (2014, 2015) recommend the countryproposing deferred acceptance mechanism by which countries would first propose visas 
for refugees, and refugees would decide whether to accept them or not in successive rounds. In practice, the mechanism simply requires collecting the preferences of both countries and refugees or asylum seekers. These preferences would take the form of a ranking of preferred destinations for refugees, in particular stating clearly which countries they would be unwilling to move to at all, and a ranking of preferred types of refugees for hosting Member States. The algorithm for the mechanism can then be programed and run in a centralized way, and the solution would be exactly the same as the solution to the game of proposals and counter-proposals.

\subsection{Comparing our proposal to existing policies: the EUREMA case}

Overall, the combination of these two elements-the tradable quotas system and the matching mechanism-results in a policy tool that has lots of theoretical advantages: costefficiency, incentive compatibility, ${ }^{3}$ and fairness in cost-sharing and in refugees' allocation. Could it work in the real world? To try to assess this, Fernández-Huertas Moraga and Rapoport (2015) concluded with a discussion of the properties of the proposed tool against the background of the EUREMA (European Relocation from Malta) Program. This program took place in 2011-12 and allowed for the relocation of about 500 refugees and asylum seekers in 15 participating countries. The selection of potential beneficiaries that were relocated was made in two steps: UNHCR first stepped in through a registration exercise, and then participating countries sent missions to Malta to make the final selection.

Importantly, from our perspective, the program was evaluated by the European Asylum Support Office (European Asylum Support Office, 2012). The evaluation report reveals important information about the conception and execution of the program. First, it is clear that substantial attention was paid to the selection criteria and demands emanating from participating countries, but candidate refugees' preferences about destinations were largely neglected. This led to long delays, frictions and inefficiency.

Second, the report listed a series of problems identified by the participating countries including: delays in the identification of candidate refugees genuinely interested in relocation; lack of overlap between the participating states' selection criteria and refugee profiles; troubles in assessing the willingness and suitability of potential beneficiaries to being relocated; unclear criteria concerning relatives and family reunification ${ }^{4}$; and lack of will by some candidates to commit to relocation offers by new EU Member States where there are few migrant communities.

As explained above, a tradable quotas system (with a matching mechanism) is precisely designed to address these problems. Following the publication of the new European Agenda on Migration, we therefore examine below how our proposal could be implemented in the quantitatively much bigger (and, arguably, politically much more sensitive) context on the Syrian refugee crisis.

\section{Simulations}

This section simulates the policy proposal described above under different scenarios related to the Syrian refugee crisis. The functional forms and main assumptions of the calculations we present are taken from Fernández-Huertas Moraga and Rapoport (2014), who simulated an extension of the US diversity visa lottery to the OECD under a similar mechanism. 


\subsection{Basic assumptions}

In particular, the cost function for country $\mathrm{i}$ of hosting $r_{i}$ new Syrian refugees that we use in the simulations below is the following:

$$
c_{i}\left(r_{i}\right)=\frac{\gamma_{i}}{2} \frac{r_{i}^{2}}{\text { pop }_{i}}
$$

The country cost $c_{i}\left(r_{i}\right)$ depends convexly on the number of refugees $r_{i}$ hosted, on the total population of the country pop $_{i}$ and on the country-specific parameter $\gamma_{i}$. The parameter $\gamma_{i}$ can be interpreted as the degree of aversion for an individual country $\mathrm{i}$ to hosting additional Syrian refugees. An advantage of this formulation is the possibility of writing the marginal cost as a linear function of the share of incoming refugees over the total population:

$$
c_{i}^{\prime}\left(r_{i}\right)=\gamma_{i} \frac{r_{i}}{\text { pop }_{i}}
$$

The remaining main ingredients of our proposal are the following:

- A total number of refugees to be resettled. In order to focus on the mechanics of the system, we confine ourselves to the little more than 40,000 Syrian refugees to be resettled pledged by EU Member States ${ }^{5}$ at the beginning of 2015. Alternatively, we could use three more ambitious proposals by François Crépeau, UN Special Rapporteur on migrant rights, Amnesty International and UNHCR, ${ }^{6}$ ranging between 130,000 and 200,000 refugees, or the one established by the European Agenda on Migration for relocating 40,000 arrivals in Greece and Italy to the rest of the European Union and resettling 20,000 refugees from third countries across all Member States (European Commission, 2015a). Since we are focusing on the Syrian crisis, we prefer to perform the simulations with the data that were referred exclusively to Syria.

- An initial distribution of quotas across countries before trading. We follow the eighth distribution key introduced in the previous section, that is, the one proposed in the European Agenda on Migration (European Commission, 2015a, 2015b).

- Preferences for refugee admissions. Following Fernández-Huertas Moraga and Rapoport (2014), we use both survey results on the willingness of natives to host additional refugees and revealed preferences, that is, the actual number of Syrian refugees pledged by European countries. The survey data correspond to the share of people in the Special Eurobarometer 380 from 2011 disagreeing with the statement: "The EU Member States should offer protection and asylum to people in need".

- A monetary reference on the cost of hosting refugees. We need a number to translate our model equations into euros. We use the per refugee quantity that the Asylum and Migration Fund provides EU member states with whenever they host an additional refugee, that is, 6000 to 10,000 euros. ${ }^{7}$ We focus on the upper bound of 10,000 euros.

For the sake of brevity, we only present fully here two of the many simulations that we have performed. The rest, in particular those with different distribution keys, are available upon request. 


\subsection{Simulation based on pledges (revealed preferences)}

Table 1 presents our first simulation. We only consider Member States who had actually pledged to host Syrian refugees as of April 2015. These Member States account for 85 percent of the total quotas assigned by the European Commission (2015a) for resettlement from third countries. The actual pledges are shown in the first data column. The second shows a distribution of quotas following the European Commission proposal for resettlement from third countries rescaled for the omission of non-pledging countries. We can see that there are countries such as Germany, Sweden, Austria and Finland pledging to host more Syrian refugees than the EU proposal would suggest, while all the rest, notably the UK, Italy or Spain, pledge to host much fewer refugees than implied by the European Commission.

Suppose countries were assigned, by our mechanism, the quotas suggested by column 2 (on the basis of the EU resettlement proposal), what are the intrinsic preferences on refugee arrivals that could generate the actual observed pledges? This question is answered in column 3. The column gives us a measure of the anti-refugee sentiment of the Member States (in proportion to their population). For example, the UK, Poland and Spain, in such a market, would have revealed themselves as the countries disliking refugees the most. On the contrary, Germany, Sweden and Austria would be revealed

Table 1 Simulation under revealed preferences: preferences are such that the market arrives at the actual number of pledges

\begin{tabular}{lcccccc}
\hline Countries & Pledges & $\begin{array}{c}\text { Initial quotas } \\
\text { (EU proposal) }\end{array}$ & $\begin{array}{c}\text { Anti-refugee } \\
\text { sentiment: deduced } \\
\text { from pledges }\end{array}$ & $\begin{array}{c}\text { Market } \\
\text { quota }\end{array}$ & $\begin{array}{c}\text { Cost reduction } \\
\text { with respect to } \\
\text { initial quota }\end{array}$ & $\begin{array}{c}\text { Cost reduction } \\
\text { with respect } \\
\text { to pledges }\end{array}$ \\
\hline Austria & 1,500 & 1,047 & 56 & 1,500 & $19 \%$ & $60 \%$ \\
Belgium & 300 & 1,156 & 372 & 300 & $55 \%$ & $-570 \%$ \\
Czech Republic & 70 & 1,238 & 1502 & 70 & $89 \%$ & $-3337 \%$ \\
Denmark & 390 & 814 & 144 & 390 & $27 \%$ & $-217 \%$ \\
Finland & 850 & 691 & 64 & 850 & $5 \%$ & $37 \%$ \\
France & 2,400 & 5,601 & 273 & 2,400 & $33 \%$ & $-267 \%$ \\
Germany & 30,000 & 7,277 & 27 & 30,000 & $975 \%$ & $151 \%$ \\
Hungary & 30 & 724 & 3303 & 30 & $92 \%$ & $-4627 \%$ \\
Ireland & 421 & 641 & 109 & 421 & $12 \%$ & $-105 \%$ \\
Italy & 450 & 4,691 & 1326 & 450 & $82 \%$ & $-1885 \%$ \\
Luxembourg & 60 & 347 & 90 & 60 & $68 \%$ & $-956 \%$ \\
Netherlands & 500 & 1,726 & 336 & 500 & $50 \%$ & $-490 \%$ \\
Poland & 100 & 2,269 & 3806 & 100 & $91 \%$ & $-4337 \%$ \\
Portugal & 93 & 1,660 & 1128 & 93 & $89 \%$ & $-3370 \%$ \\
Spain & 130 & 3,653 & 3594 & 130 & $93 \%$ & $-5420 \%$ \\
Sweden & 2,700 & 1,158 & 35 & 2,700 & $177 \%$ & $114 \%$ \\
United Kingdom & 143 & 5,445 & 4469 & 143 & $95 \%$ & $-7416 \%$ \\
Total & 40,137 & 40,137 & & 40,137 & $92 \%$ & $0 \%$ \\
Quotas traded & & & $62 \%$ & & \\
\hline Non & & & & $63 \%$ & \\
\hline
\end{tabular}

Notes: Countries included are EU Member States that pledged to host Syrian refugees as of April 2015; pledges refer to the number of Syrian refugees they pledged to host as of April 2015; initial quotas are calculated by rescaling the EU proposal on resettlement for the omission of non-pledging countries; anti-refugee sentiment calculated as population over pledge divided by 1 million; market quota is the market allocation in this simulation given the assumptions 
as the most refugee-friendly countries. How do we attain this number? We would just need to equate marginal costs across countries to the market-clearing price so that:

$$
c_{i}^{\prime}\left(r_{i}^{\text {pledged }}\right)=\gamma_{i}^{\text {revealed }} \frac{r_{i}^{\text {pledged }}}{\text { pop }_{i}}=p
$$

From this, we can get $\gamma_{i}^{\text {revealed }}$ as:

$$
\gamma_{i}^{\text {revealed }}=\frac{\text { pop }_{i}}{r_{i}^{\text {pledged }}}
$$

The number shown in column 3 is the $\gamma_{i}^{\text {revealed }}$ calculated as explained above and divided by 1 million to make it readable.

About 62 percent of all the quotas allocated according to column 2 would be traded, generating an overall 92 percent cost reduction with respect to the EU distribution of quotas. By definition, the total cost would not vary with respect to the pledges from column 1, but the distribution of costs would certainly change substantially. The market would benefit Germany, Sweden and Austria, who would be paid by countries such as the UK, Spain and Hungary.

In monetary terms, we can take the polar cases of Germany and the UK. Suppose that we equate the marginal cost of the market to 10,000 euros, the per-refugee compensation given by the Asylum and Migration Fund. The total cost, both under the existing pledges and under the market, would be equal to 40,137 pledges times 10,000 euros, that is 201 million euros. Under the current system of pledges, Germany's cost would be equal to 150 million while the UK's cost would be limited to 715,000 euros. If the market were to be implemented, though, Germany would actually turn a profit of 77 million euros, while the UK's cost would rise to 54 million.

\subsection{Simulation based on Eurobarometer replies (stated preferences)}

Of course, the simulation above is a very particular one. We can next assume that preferences have not been revealed by the current pledges but, instead, the true preferences of the Member States were reflected in the answers of their citizens to the Eurobarometer 380 (2011) question on the appropriateness of granting asylum to people in need. This exercise is performed in Table 2, where the taste parameter $\gamma_{i}$ is no longer calculated but is taken instead as a given characteristic of each of the countries:

In this case, only a quarter of the initial distribution of quotas would be traded. The reason is that the differences in preferences are not as extreme as in Table 1. The difference between the most refugee-friendly country (Sweden) and the less refugee-friendly one (Hungary) is less than 8 to 1 , compared to 166 to 1 (Germany vs. the UK) in Table 1 . Given that there would be fewer trades, the total cost reduction with respect to the initial EU quotas is smaller than in Table 1, just 27 percent instead of 62 percent.

The main difference would come from the comparison with the cost associated to existing pledges. The market would imply a cost reduction of 65 percent with respect to the voluntary pledges. The reason is that the pledges are very far from the optimal solution implied by the market. In other words, the pledges would be very different from Member States' true preferences, if the true preferences are correctly reflected in the Eurobarometer survey. The simulation is run under the assumption that countries' true cost corresponds to these preferences rather than to the revealed ones from Table 1. 
Table 2 Simulation under stated preferences: share of people in the special Eurobarometer 380 from 2011 disagreeing with the statement: "The EU member states should offer protection and asylum to people in need"

\begin{tabular}{|c|c|c|c|c|c|c|}
\hline Countries & Pledges & $\begin{array}{l}\text { Initial quotas } \\
\text { (EU proposal) }\end{array}$ & $\begin{array}{l}\text { Anti-refugee sentiment } \\
\text { Eurobarometer } 2011\end{array}$ & Market quota & $\begin{array}{c}\text { Cost reduction } \\
\text { with respect to } \\
\text { initial quota }\end{array}$ & $\begin{array}{c}\text { Cost reduction } \\
\text { with respect to } \\
\text { pledges }\end{array}$ \\
\hline Austria & 1,500 & 1,047 & 19 & 525 & $25 \%$ & $63 \%$ \\
\hline Belgium & 300 & 1,156 & 27 & 488 & $33 \%$ & $-888 \%$ \\
\hline Czech Republic & 70 & 1,238 & 22 & 564 & $30 \%$ & $-21914 \%$ \\
\hline Denmark & 390 & 814 & 7 & 945 & $3 \%$ & $-324 \%$ \\
\hline Finland & 850 & 691 & 12 & 534 & $5 \%$ & $37 \%$ \\
\hline France & 2,400 & 5,601 & 26 & 2,976 & $22 \%$ & $-325 \%$ \\
\hline Germany & 30,000 & 7,277 & 11 & 8,801 & $4 \%$ & $94 \%$ \\
\hline Hungary & 30 & 724 & 31 & 377 & $23 \%$ & $-44781 \%$ \\
\hline Ireland & 421 & 641 & 15 & 361 & $19 \%$ & $-88 \%$ \\
\hline Italy & 450 & 4,691 & 17 & 4,144 & $1 \%$ & $-10617 \%$ \\
\hline Luxembourg & 60 & 347 & 14 & 45 & $76 \%$ & $-715 \%$ \\
\hline Netherlands & 500 & 1,726 & 19 & 1,042 & $16 \%$ & $-905 \%$ \\
\hline Poland & 100 & 2,269 & 7 & 6,418 & $335 \%$ & $120790 \%$ \\
\hline Portugal & 93 & 1,660 & 13 & 952 & $18 \%$ & $-25971 \%$ \\
\hline Spain & 130 & 3,653 & 9 & 6,128 & $46 \%$ & $-42607 \%$ \\
\hline Sweden & 2,700 & 1,158 & 4 & 2,820 & $206 \%$ & $119 \%$ \\
\hline United Kingdom & 143 & 5,445 & 25 & 3,017 & $20 \%$ & $-116062 \%$ \\
\hline Total & 40,137 & 40,137 & & 40,137 & $27 \%$ & $65 \%$ \\
\hline Quotas traded & & & & $25 \%$ & & \\
\hline
\end{tabular}

Notes: Countries included are EU Member States that pledged to host Syrian refugees as of April 2015; pledges refer to the number of Syrian refugees they pledged to host as of April 2015; initial quotas are calculated by rescaling the EU proposal on resettlement for the omission of non-pledging countries; anti-refugee sentiment calculated as the share of people in the Special Eurobarometer 380 from 2011 disagreeing with the statement: "The EU Member States should offer protection and asylum to people in need;" market quota is the market allocation in this simulation given the assumptions

In monetary terms, if we maintain the assumption that the marginal cost of the market equates the 10,000 per-refugee compensation from the Asylum and Migration Fund, then the total cost of the market would still be 200 million euros as in Table 1 . As a result, we would infer the actual cost of the existing pledges to be 568 million euros according to our simulated cost functions.

Considering again the polar cases in this simulation, the most benefitted country with respect to the existing pledges would be Poland, which would actually earn 9 million euros through the market. Sweden would be the only other country to turn a profit. The reason is that residents of both countries declare to be particularly refugeefriendly, and this translates into a low cost of hosting refugees for them. Hence, they get paid a large sum by less refugee-friendly countries. On the opposite side, the UK would have the largest cost increase, from 34,000 euros to 39 million euros, although the biggest cost overall would correspond to France, with 41 million euros.

\subsection{General discussion}

It is important to stress that the simulations above are for illustrative purpose only. We have (nor anyone has) any definitive evidence as to what countries preferences are in 
reality (not to mention that governments can opt for policies that are only imperfectly reflecting people's preferences) or what cost-functions they imply. Actually, only a market-mechanism of the type we are proposing is able to reveal the true cost for countries of hosting additional refugees-and to result in a sensible "price" that can guide public decision-making.

Still, even though both approaches give us different results in terms of the efficiency of the market and the final distribution of costs that it would generate, they are useful in understanding the difficulties the $\mathrm{EU}$ is having in coordinating a response to the Syrian crisis. Both approaches conclude that a majority of countries lose with respect to an uncoordinated solution, at least given the initial distribution of quotas that has been proposed by the European Union. There are very few countries, mostly Germany and Sweden, that would actually benefit from a coordinated solution even if this was globally efficient as in our simulation presented in Table 2 . This suggests that the initial distribution of quotas would need to be adjusted to make sure that all the Member States, or at least a majority of them, benefit from the coordinated policy. This is feasible as long as there are global gains, but it would require a level of information that it is unlikely to be available.

Given these considerations, we do not advocate a full implementation of our system to begin with. Instead, we believe our proposal should be tested on a reduced number of refugees, and possibly member states, before scaling it up. The objective would be to show that it actually generates substantial welfare gains both for refugees and for participating member states. It would also allow us to elicit some useful information on how to manipulate initial quotas so that a larger number of participating countries benefit from the market.

\section{Conclusion}

The Common European Asylum System had been struggling to coordinate policies across Member States for a long time, but the refugee flights generated by the war in Syria made its problems more apparent and their solution more urging. The current paper takes the theoretical model developed in Fernández-Huertas Moraga and Rapoport (2014) and adapted by Fernández-Huertas Moraga and Rapoport (2015) to the coordination of the reception of refugees and asylum seekers in the European Union and goes on to simulate how it would work in the context of the Syrian refugee crisis.

Our proposal consists of three main elements. The first one is a distribution of responsibilities across Member States according to some criterion. This issue has already been tackled by the European Commission when launching their European Agenda on Migration. Secondly, we argue that refugee preferences need to be taken into account by allowing them to choose their preferred destination within the European Union as long as there are refugee quotas available. Similarly, receiving countries preferences regarding refugee types could also be taken into account. We would implement this choice through the adoption of one of the classical matching mechanisms that have been typically used to assign students to colleges or doctors to hospitals. Thirdly, allowing Member States to trade the quotas assigned by the European Commission would ensure that refugees end up going to the countries where it is less costly or more beneficial to host them. 
Our paper simulates two potential outcomes of such a market under different assumptions on the actual cost functions of countries. We take two approaches to simulate the cost functions: a revealed preferences approach, deducing preferences from pledges to host Syrian refugees that were made at the beginning of 2015; and a stated preferences approach, taking average answers across countries about refugee protection from Eurobarometer surveys. Of course, both simulations give rise to very different outcomes. Nevertheless, they are helpful to understand the potential costs and benefits that such a system may have for individual countries, which explains why some of them might be more or less in favor of coordinated solutions. We argue that this potential variety of outcomes is a rationale for policy experiments that would include our proposal.

As a way forward, we advocate the market component of our proposal as a solution to the lack of flexibility of the existing EU system and of the European Agenda on Migration. The market would allow Member States to modulate their contribution to the CEAS in terms of reception of refugees or just financial compensations according to their own different preferences and particular situations in different points in time. The market does not imply that countries can shy away from their responsibility in providing protection. It just gives them additional maneuvering space in contributing to the general public good.

Furthermore, the inclusion of the matching mechanism ensures the protection of individual refugee rights so that none of them are forced to relocate to an undesired destination. Moreover, the opportunity to express preferences offers additional opportunities to increase efficiency for both refugees and receiving countries, which can be used either to reduce overall costs or to increase the total number of refugees receiving protection in the European Union.

\section{Endnotes}

${ }^{1}$ http://www.unhcr.org/55016fff6.html

${ }^{2}$ http://www.unhcr.org/551aa6736.html

${ }^{3}$ The mechanism is conceived in such a way that it is "incentive compatible;" that is, it generates a truthful revelation of preferences, both of the migrants (refugees) and the countries.

${ }^{4}$ This feature is not specifically considered in our paper but can be easily incorporated. For example, Roth (2002) explains how classical matching mechanisms can be modified to take into account the assignment of couples to residency positions in the US.

${ }^{5}$ Data from http://www.resettlement.eu/news/crisis-syria. Web accessed on 4-13-2015.

${ }^{6} \mathrm{http}: / /$ www.independent.co.uk/news/world/middle-east/syrian-refugees-with-fourmillion-people-languishing-in-camps-in-turkey-lebanon-and-jordan-the-un-calls-fororganised-quota-system-10031404.html

${ }^{7}$ http://www.resettlement.eu/page/eu-funding-resettlement-erfamif

The IZA Journal of European Labor Studies is committed to the IZA Guiding Principles of Research Integrity. The authors declare that they have observed these principles. 
Phillipe De Bruycker and to Philippe Fargues for their comments. Jesús Fernández-Huertas Moraga received financial support from the ECO2012-39412 project funded by the Spanish Ministry for Economics and Competitiveness. Responsible editor: Martin Kahanec.

\section{Author details}

${ }^{1}$ Universidad Autónoma de Madrid, Madrid, Spain. ${ }^{2}$ IZA, Bonn, Germany. ${ }^{3}$ Paris School of Economics, Université Paris 1 Panthéon-Sorbonne, Paris, France. ${ }^{4}$ Migration Policy Center, European University Institute, San Domenico de Fiesole, Fiesole, Italy.

Received: 1 September 2015 Accepted: 23 October 2015

Published online: 27 November 2015

\section{References}

Abdulkadiroglu A, Sonmez T (1999) House Allocation with Existing Tenants. J Econ Theory 88:233-260

De Bruycker et al. (2010) Setting up a Common European Asylum System: Report on the application of existing instruments and proposal for the new system. Publications Office of the European Union, Luxembourg

European Asylum Support Office (2012) EASO fact finding report on intra-EU relocation activities from Malta., Retrieved from http://easo.europa.eu. July 2012

European Commission (2015a) A European Agenda on Migration. Communication from the Commission to the European Parliament, the Council, the European Economic and Social Committee and the Committee of the Regions. Brussels, 13.5.2015, COM (2015) 240 final

European Commission (2015b) Proposal for a Council Decision establishing provisional measures in the area of international protection for the benefit of Italy and Greece. Brussels, 27.5.2015, COM (2015) 286 final

Fargues P, and Bonfanti S (2014) When the best option is a leaky boat: why migrants risk their lives crossing the Mediterranean and what Europe is doing about it. Migration Policy Centre Policy Brief 2014/05, October

Fargues P and Di Bartolomeo A (2015) Drowning Europe. Migration Policy Centre Policy Brief 2015/05, April

Fernández-Huertas Moraga J, Rapoport H (2014) Tradable Immigration Quotas. J Pub Econ 115:94-108

Fernández-Huertas Moraga J,. Rapoport H (2015) Tradable Refugee-admission Quotas and EU Asylum Policy, CESifo Economic Studies, 61(3-4):638-672

Hatton TJ (2012) Asylum Policy in the EU: the case for deeper integration, Norface Migration Discussion Paper No. 2012-16

Roth AE (2002) The Economist as an Engineer: Game Theory, Experimental Economics and Computation as Tools of Design Economics. Econometrica 70(4):1341-1378

Thielemann E R Williams R C Boswell; and Matrix Insight Ltd. (2010) What system of burden-sharing between Member States for the reception of asylum seekers?. Study. Directorate General for Internal Policies, Policy Department C: Citizens' Rights and Constitutional Affairs, Civil Liberties, Justice and Home Affairs, European Parliament, Brussels

Wagner M, Kraler A (2014) An Effective Asylum Responsibility-Sharing Mechanism, ICMPD Asylum Programme for Member States - Thematic Paper

\section{Submit your manuscript to a SpringerOpen ${ }^{\circ}$ journal and benefit from:}

- Convenient online submission

- Rigorous peer review

- Immediate publication on acceptance

- Open access: articles freely available online

- High visibility within the field

- Retaining the copyright to your article 